\title{
Title: Sexual inactivity in partnered female cancer survivors
}

Authors: Jennifer L. Marino, MPH, $\mathrm{PhD}^{1,4}$, Christobel M. Saunders, MB BS Lond., FRCS, FRACS $^{2,3}$, Martha Hickey, MBChB, MD, FRANZCOG ${ }^{1}$

${ }^{1}$ Department of Obstetrics and Gynaecology, The University of Melbourne, Parkville, Victoria, Australia and the Royal Women's Hospital, Victoria, Australia

${ }^{2}$ School of Surgery, The University of Western Australia, Crawley, Western Australia, Australia

${ }^{3}$ Menopause Symptoms after Cancer Clinic, King Edward Memorial Hospital, Subiaco, Western Australia, Australia

${ }^{4}$ To whom correspondence should be addressed at: jennifer.marino@unimelb.edu.au Postal address: Department of Obstetrics \& Gynaecology, The University of Melbourne, Royal Women's Hospital, Level 7, 20 Flemington Rd, Parkville, Victoria, 3052, AUSTRALIA Phone: +61-3-8345-3718

Fax: +61-3-8345-3702 


\section{Abstract \\ Objective}

To measure sexual activity in a clinic population of partnered female cancer survivors, and to better understand reasons for sexual inactivity in this population.

Materials and methods

Partnered peri- or post-menopausal cancer survivors seen at a specialty clinic for menopause symptoms after cancer completed Fallowfield's Sexual Activity Questionnaire, quality of life measures (the Functional Assessment of Cancer Therapy General, Breast Cancer, and Endocrine Symptom Scales), and the Greene Climacteric Scale. Responses were compared between those who were sexually active and those who were not.

Results

Of 316 partnered women who reported sexual activity status, most were breast cancer survivors $(n=268,85 \%)$ and were sexually active $(n=227,72 \%)$. Women who were not sexually active $(\mathrm{n}=89,28 \%)$ were slightly older than those who were active $(53.1 \vee 51.0$ years, $\mathrm{p}=0.049)$ but did not differ in menopausal status, time since cancer diagnosis, or treatment with chemotherapy, anti-estrogenic endocrine therapy or menopausal hormone therapy. Loss of interest in sex (78\%) and being too tired (44\%) were the most common reasons for sexual inactivity. Those who were not sexually active were more likely to be dissatisfied with their sex lives (adjusted odds ratio (aOR) 3.52, 95\% CI 1.66-7.48) and to have lost interest in sex (aOR $2.12,95 \%$ CI 1.22-3.67). Sexually inactive women were significantly less likely to feel sexually attractive or "able to feel like a woman" (respectively, aOR 2.51, 95\% CI 1.01-6.24; aOR 2.21, 95\% CI 1.32-3.71) and more likely to feel bothered by a weight change, selfconscious about the way they dressed, and bothered by hair loss than sexually active women (respectively, aOR 1.84, 95\% CI 1.10-3.05; aOR 2.75, 95\% CI 1.63-4.64; aOR 1.85, 95\% CI 1.04-3.29). Those who were not sexually active had significantly lower average scores on 
breast-cancer-related quality of life than sexually active women but did not differ in physical, social or functional well-being or menopause related quality of life. Pain with intercourse and vaginal dryness were equally common in both groups (respectively, sexually inactive $45.5 \% \mathrm{v}$. active $38.3 \%$, aOR $1.28,95 \%$ CI $0.75-2.18 ; 48.8 \%$ v. $49.5 \%$, aOR $0.94,95 \%$ CI $0.57-1.56$. Conclusions

Over one quarter of partnered cancer survivors in this clinic-based sample were not sexually active. Sexually inactive women were more dissatisfied with their sex lives, felt less attractive and more self-conscious about their appearance. The reasons for sexual inactivity in cancer survivors are multifaceted and complex and rates of vaginal dryness and dyspareunia did not differ between sexually active and inactive women, suggesting that interventions to improve sexual function which are limited to treating vaginal dryness are unlikely to be effective. Keywords sexual activity, sexual dysfunction, menopause, libido, sexual satisfaction 


\section{$\underline{1 . \text { Introduction }}$}

Worldwide, 15 million women are cancer survivors [1]. Breast and colorectal cancers are the most common cancers in women [2], and treatment for both is associated with sexual dysfunction [3-7]. In the general postmenopausal female population, whilst pain with vaginal intercourse, low sexual desire and other sexual dysfunction are common, many women continue to be sexually active $[8,9]$. Sexual frequency is known to decrease after menopause [10] and as women (and their partners) age [11-13], but the relationship between sexual dysfunction and sexual inactivity is not well understood. In one study of women treated for breast cancer with aromatase inhibitors, $79 \%$ developed a new sexual problem, of whom nearly a quarter discontinued sexual activity [14]. Less is known about how other cancer treatments impact on sexual activity. Existing literature $[3,15,16]$, clinical experience, and our previous work [17-19] suggest that amongst sexually active female cancer survivors, sexual distress is common, particularly in those who do not use menopausal hormone therapy (MHT). The proportion of women who stop being sexually active with their partners after cancer treatment is unknown. The aim of this study was to measure sexual activity in partnered female cancer survivors and to better understand quality of life and underlying reasons for sexual inactivity. 


\section{Materials and Methods}

\subsection{Study population}

The multidisciplinary Menopause Symptoms After Cancer (MSAC) clinic [20, 21] at King Edward Memorial Hospital, Western Australia serves a population of over 2 million. Women attending the clinic between 2003 and 2010 were invited to participate in collection of data regarding menopausal symptoms, past and current treatment, reproductive history, and cancer history $[17,18]$. The study was approved by the institutional ethics committee and informed consent obtained at the time of recruitment.

\subsection{Measurement of patient characteristics}

Detailed methods of data collection have been reported previously [18]. Sexual function was reported using Fallowfield's Sexual Activity Questionnaire (SAQ) [22]. The first section of the instrument, completed by all respondents, asks if a woman is currently married or having an intimate relationship ("partnered"), whether she has changed sexual partner in the prior 6 months, and whether she currently engages in sexual activity. The second section, completed only by respondents who have reported they are not currently sexually active, offers a list of reasons for inactivity plus a free text field. Listed reasons include lack of a partner, being too tired, lack of interest in sex, "physical problem that makes sexual relations difficult or uncomfortable", and the corresponding problems for partners.

Information regarding problems that may affect sexual activity was drawn from the Functional Assessment of Cancer Therapy General (FACT-G) [23], Breast Cancer (BCS) [24], and Endocrine Symptom Scales (ESS) [25], and the Greene Climacteric Scale (GCS) [26]. The FACT-G provides global quality of life scores including Physical Well-Being (PWB), Social/Family Well-Being (SWB), and Functional Well-Being (FWB) (all 7-item scores). The 19-item ESS measures health-related quality of life specific to menopausal symptoms. The 9item BCS measures breast-cancer-related quality of life, but most items assessed in the BCS 
are issues that may be faced by women with other types of cancer (e.g. shortness of breath, weight change, feeling self-conscious about appearance). Higher scores correspond to better function. For individual items, we created binary variables. For negatively stated items (e.g. "I am bothered by hair loss"), we compared those who reported having problems "a little bit" or "not at all" (reference group) to those who had them "somewhat," "quite a bit," or "very much." For the five positively stated items, "I am sleeping well," "I feel sexually attractive," "I am satisfied with my sex life," "I feel close to my partner," and "I am able to feel like a woman," we compared those who reported having the experience "quite a bit" or "very much" (reference group) to those who had them "somewhat," "a little bit" or "not at all." For reasons of clarity and consistency, these items are presented in negative statement (problem) format in the tabulated section of the Results.

Symptoms of anxiety and depression were drawn from the respective domains of the GCS defined by Greene in 1998 [26]. Those who endorsed "quite a bit" or "extremely" (versus "a little bit" or "not at all") for 4 or more of the 6 anxiety symptoms were categorized as having anxiety symptoms, and for 3 or more of the 5 depression symptoms were categorized as having depression symptoms.

Gynaecologic history and history of previous treatment for menopausal symptoms were recorded at the first visit. Current menopausal status and menopausal status before and after cancer treatment was collected at interview and classified according to current Stages of Reproductive Aging Workshop (STRAW) criteria [27]. For those who were hysterectomised, this was defined as new onset vasomotor symptoms following endocrine or chemotherapy. Those whose reproductive status could not be defined and those who were premenopausal were excluded from this study. Surgical date was used as a proxy for date of cancer diagnosis to calculate age at diagnosis.

\subsection{Statistical analysis}


Categorical variables were summarised using frequency and percentage, and continuous variables using means and standard deviations. Demographic and clinical characteristics were compared between those who were and were not sexually active using t-test for continuous variables, Fisher's exact test for binary variables, and chi-squared tests for categorical variables. We compared the mean values and 95\% confidence intervals $(\mathrm{CI})$, adjusted for age, of each of the PWB, FWB, SWB, BCS and ESS scores between women who were and were not sexually active. For select individual items drawn from the instruments, we examined the likelihood of having problems using odds ratios (OR) and their 95\% confidence intervals, adjusted for age and menopausal status. Data analysis was conducted using Stata v.14.2 (StataCorp. 2017. Stata Statistical Software: Release 14. College Station, TX: StataCorp LP), All hypothesis tests were two-sided and $\mathrm{p}$-values $<0.05$ were considered statistically significant.

\section{$\underline{3 \text { Results }}$}

\subsection{Study population}

Of 903 peri- and post-menopausal patients seen in the MSAC clinic, 407 (45.1\%) completed some part of the first section of the SAQ. Of these, 400 reported both sexual activity and partner status. Nearly all sexually active women $(n=227 / 228,99.6 \%)$ and half who were inactive $(\mathrm{n}=89 / 172,51.7 \%)$ identified as being married or in an intimate relationship $(\mathrm{p}<0.001)$. This analysis is limited to these partnered women. Of 316 partnered women who reported sexual activity status, $89(28.1 \%)$ were not sexually active. Of these, $5(1.6 \%)$ had changed partners in the previous six months. The distribution of cancer types in partnered women is shown in Figure 1. In common with most women attending this clinic, the majority were breast cancer survivors $(\mathrm{n}=268,84.8 \%)$. No other single cancer type (endometrial, ovarian, colorectal, cervical, pancreatic, multiple myeloma) constituted more than $2 \%$ of the sample. Of those who reported more than one type of cancer $(n=21,6.6 \%)$, all but two had breast and another cancer (7 skin, 3 cervical, 3 ovarian, 2 gestational, 2 lymphoma, 2 leukaemia, 1 renal); the two 
exceptions reported a colorectal and a gestational cancer, and a thyroid and an endometrial cancer.

Table 1 lists participant demographic and clinical characteristics by sexual activity status. Women who were sexually active were slightly younger than those who were not (51.0 v 53.1 years, $\mathrm{p}=0.049$ ). There were no significant differences in marital status, menopausal status, and time since cancer diagnosis, treatment with chemotherapy, endocrine therapy, or current MHT.

\subsection{Sexual inactivity}

Figure 2 illustrates the reasons that women were not sexually active. Loss of interest in sex $(n=69,77.8 \%)$ was the most common reason. Feeling too tired $(n=39,43.8 \%)$ was the next most common reason. Participants more often listed reasons related to themselves than to their partners (self only $n=51,57.3 \%$, self and partner $n=27,30.3 \%$, partner only $n=11,12.4 \%$ ). Reasons specified in the "Other" category included decreased libido $(n=2)$, vaginal dryness $(n=2)$, painful intercourse $(n=1)$, painful skin after radiotherapy $(n=1)$, feeling depressed $(n=2)$, feeling tense and nervous $(n=1)$, feeling neglected $(n=1)$, not feeling sexy $(n=1)$, emotional unreadiness $(n=1)$, body image/self-esteem issues $(n=1)$, recent hysterectomy $(n=1)$, beta blocker use $(n=1)$, partner lack of interest $(n=2)$, partner working at a distance $(n=2)$, and unhappy relationship $(\mathrm{n}=1)$.

Table 2 describes comparisons of quality of life scales by sexual activity group after adjustment for age. Breast cancer survivors who were not sexually active had significantly lower mean scores on breast-cancer-related quality of life than sexually active women but did not differ in other measures of quality of life.

Table 3 presents comparisons of specific symptoms by sexual activity after adjustment for age. The majority of women were dissatisfied with their sex lives, but those who were not sexually active were more likely to be dissatisfied than sexually active women $(89.2 \%$ v. $70.0 \%$, adjusted odds ratio (aOR) 3.52, 95\% CI 1.66-7.48). Loss of interest in sex was more common 
among women who were not sexually active than among sexually active women $(73.3 \% \mathrm{v}$. $55.2 \%$, aOR $2.12,95 \%$ CI 1.22-3.67). Most women felt close to their partners (78.4\% sexually inactive, $82.1 \%$ sexually active), and this did not differ by sexual activity status. Participants who were not sexually active were significantly less likely to feel sexually attractive or feel like a woman (respectively, $93.2 \%$ v. $84.8 \%$ aOR $2.51,95 \%$ CI $1.01-6.24 ; 64.8 \%$ v. $46.4 \%$, aOR 2.21, 95\% CI 1.32-3.71) and more likely to feel bothered by a weight change, selfconscious about the way they dressed, and bothered by hair loss than sexually active women (respectively, $59.5 \%$ v. $46.4 \%$, aOR $1.84,95 \%$ CI $1.10-3.05 ; 51.1 \%$ v. $29.9 \%$, aOR $2.75,95 \%$ CI $1.63-4.64 ; 29.5 \%$ v. $19.1 \%$, aOR $1.85,95 \%$ CI 1.04-3.29). Shortness of breath was more common, and night sweats were less common among women not sexually active than among sexually active women (respectively, $23.6 \%$ v. $12.6 \%$, aOR $1.95,95 \%$ CI $1.03-3.71 ; 63.6 \%$ v. 75.9\%, aOR 0.56, 95\% CI 0.33-0.96). Pain with intercourse and vaginal dryness were equally common in both groups (respectively, sexually inactive $45.5 \%$ v. active $38.3 \%$, aOR 1.28 , 95\%CI $0.75-2.18 ; 48.8 \%$ v. $49.5 \%$, aOR $0.94,95 \%$ CI $0.57-1.56)$. Other physical problems, including pain and lack of energy, did not differ by group. Depressive symptoms were more common among women not sexually active than among sexually active women $(29.4 \% \mathrm{v}$. $16.6 \%$, aOR $2.14,95 \%$ CI 1.18-3.89).

\section{Discussion}

Over a quarter of partnered peri- and postmenopausal women seen in a menopause symptoms after cancer clinic (MSAC) reported that they were not sexually active. Although no national data are available for partnered women in Australia, this is substantially higher than nationally representative estimates of partnered women aged 50-59 in the Survey of Midlife Development in the United States, 13.2\% [28]) and in the English Longitudinal Study of Ageing (13.9\% [11]). It is also higher than reported levels of sexual inactivity in partnered non-cancer patients attending a menopause clinic (16.7\%, unpublished data.) In a second study using English 
Longitudinal Study of Ageing data [29], partnered female cancer survivors were no less likely to be sexually active than partnered women without cancer, after adjustment for age. In that study, the mean age of female participants was substantially higher than in the present study (cancer survivors 60.4 years, controls 64.4 years) which is likely to have affected sexual activity. Differences in cancer type could account for this discrepancy, but the English study did not report prevalence of cancer type by gender.

In our study, sexually inactive women were more dissatisfied with their sex lives than sexually active women. This is consistent with the Survey of Midlife Development in the United States, which found that, in healthy partnered women, sexual satisfaction was lower among women who had not been sexually active in the prior 6 months [28]. We did not have a direct measure of sexual distress, but sexual distress is known to be associated with sexual dissatisfaction and avoidance [30]. The level of sexual dissatisfaction was high in sexually active and inactive women $(70 \%)$, consistent with the observation that female cancer survivors are more likely to be dissatisfied with their sex lives than healthy controls [29]. Sexual activity was not associated with feeling close to one's partner. Other investigators have found that women's sexual dysfunction decreases the sexual function of partners [31], and that women's sexual dysfunction causes more sexual distress among partnered than unpartnered women [32], suggesting that partnered women who encounter sexual difficulties after cancer may have a fundamentally different relationship to sexual inactivity than unpartnered ones. Our study found that personal rather than partner factors were more likely to affect sexual activity in cancer survivors, but partnership status and partner health should also be considered.

We found no difference in physical, social or functional well-being, nor quality of life related to menopausal symptoms, between sexually active and inactive cancer survivors. We did find that sexually inactive women scored significantly lower in breast cancer-related quality of life particularly aspects of self-image that are likely to be common across cancer streams. We 
observed that feeling self-conscious about dress, not feeling like a woman, being bothered by hair loss, and not feeling sexually attractive, were more common in sexually inactive women. However, we are unable to determine cause and effect. It is well-established that cancer and its treatment can have effects on sexual self-image $[33,34]$, but not how this impacts on sexual function and activity.

More than three-quarters of partnered participants reported their reason for not being sexually active was loss of interest in sex. Being too tired was also a common reason for not engaging in sexual activity, but low energy was equally common in both groups. Depressive symptoms were associated with sexual inactivity, as is seen in healthy women [35]. A novel observation from this study was that vaginal dryness and pain with intercourse were equally common in sexually active and inactive women, suggesting that this problem alone does not account for sexual inactivity.

Strengths of this study include its relatively large size and its use of validated patient-reported outcome measures. Limitations include the relatively low response rate to the SAQ (45\%), the cross-sectional design, and our selected clinical population of women seeking treatment for menopausal symptoms after cancer. As this population is limited to those who have cancers causing or requiring treatment causing menopausal symptoms, the distribution of cancer in this group does not reflect the distribution of cancers in developed countries. Some cancers whose treatment may result in sexual problems independent of menopausal symptoms, such as colorectal and gynaecologic cancers, are not well-represented, which may affect findings. 


\section{$\underline{5 . \text { Conclusions }}$}

Over one quarter of partnered cancer survivors in this clinic-based sample were not sexually active. Sexually inactive women were more dissatisfied with their sex lives, and felt less attractive and more self-conscious about their appearance. The reasons for sexual inactivity in cancer survivors are multifaceted and complex and vaginal problems such as a dryness and dyspareunia did not appear to account for sexual inactivity, suggesting that interventions to improve sexual function which are limited to treating vaginal dryness are unlikely to be effective. 
Table 1. Demographic and clinical characteristics of participants

\begin{tabular}{|c|c|c|c|}
\hline & $\begin{array}{l}\text { Not sexually active } \\
\mathrm{N}=89\end{array}$ & $\begin{array}{l}\text { Sexually active } \\
\mathrm{N}=227\end{array}$ & $p$ \\
\hline Mean age (SD) & $53.1(8.8)$ & $51.0(8.0)$ & 0.049 \\
\hline Marital status, N (\%) & & & 0.2 \\
\hline Married or de facto & $82(96.5)$ & $194(90.7)$ & \\
\hline $\begin{array}{l}\text { Separated, widowed, or } \\
\text { divorced }\end{array}$ & $2(2.4)$ & $8(2.8)$ & \\
\hline Never married & $1(1.2)$ & $16(6.5)$ & \\
\hline $\begin{array}{l}\text { Time since cancer diagnosis, } \mathrm{N} \\
(\%)\end{array}$ & & & 0.2 \\
\hline$<1$ year & $31(35.6)$ & $103(46.0)$ & \\
\hline $1-<2$ years & $28(32.2)$ & 49 (21.9) & \\
\hline $2-<5$ years & $17(19.5)$ & $49(21.9)$ & \\
\hline $5+$ years & $11(12.6)$ & $23(10.3)$ & \\
\hline Menopausal status & & & 0.3 \\
\hline Perimenopausal & $7(7.9)$ & $27(11.9)$ & \\
\hline Postmenopausal & $82(92.1)$ & $200(88.1)$ & \\
\hline $\begin{array}{l}\text { Ever treated with } \\
\text { chemotherapy, } \mathrm{N}(\%)\end{array}$ & $49(55.1)$ & $127(55.9)$ & 0.9 \\
\hline $\begin{array}{l}\text { Currently treated with } \\
\text { endocrine therapy, } \mathrm{N}(\%)\end{array}$ & $34(38.2)$ & $108(47.6)$ & 0.1 \\
\hline Breast cancer surgery* & & & 0.2 \\
\hline Wide local excision only & $45(58.4)$ & $127(63.5)$ & \\
\hline
\end{tabular}




\begin{tabular}{c|l|l|l}
\hline \multicolumn{1}{c|}{ Single mastectomy } & $21(27.3)$ & $58(29.0)$ & \\
\hline Double mastectomy & $11(14.3)$ & $15(7.5)$ & \\
\hline Breast reconstruction * & & $7(3.1)$ & \\
\hline Currently treated with systemic & $3(3.4)$ & & \\
menopausal hormone therapy, & & & \\
$\mathrm{N}(\%)$ & $0(0)$ & $3(1.3)$ & 0.3 \\
\hline Currently treated with vaginal & & & \\
oestrogen, N (\%) & & $27(11.9)$ & \\
\hline Currently treated with SSNRI, & $11(12.4)$ & & \\
N(\%) & & & \\
\hline
\end{tabular}

* Breast cancer patients only 
Table 2. Comparison of mean quality of life scores by sexual activity

\begin{tabular}{l|l|l|l}
\hline & Not sexually & Sexually active & Adjusted score \\
& active & & difference \\
\hline & Mean, SD & Mean, SD & Beta (95\% CI) \\
\hline Physical well-being & 89 & 224 & $-0.65(-2.11,0.81)$ \\
\hline Functional well-being & $20.05,5.61$ & $20.57,6.01$ & \\
\hline Social/family well-being & 86 & 223 & $-1.13(-2.60,0.33)$ \\
& $15.93,5.81$ & $16.93,5.86$ & \\
\hline Breast cancer-related quality of & 89 & 224 & $-1.28(-2.78,0.21)$ \\
life & $21.27,6.53$ & $24.46,6.25$ & \\
\hline Menopausal-symptom-related & 88 & $19.70,6.01$ & \\
\hline quality of life & $48.57,11.62$ & $50.98,9.76$ & \\
\hline & & & \\
\hline
\end{tabular}


Table 3. Specific problems by sexual activity. Other than for originally positive items, marked with an asterisk, proportion presented is those who had the problem "somewhat", "quite a bit" or "very much". Denominators vary as participants did not answer every question. Odds ratios are adjusted for age.

\begin{tabular}{l|l|l}
\hline Problem & Not sexually active & Sexually active \\
$\mathrm{N}(\%)$ & $\mathrm{N}(\%)$ \\
& OR $(95 \% \mathrm{CI})$ & \\
\hline
\end{tabular}

Sexual problems and genital symptoms

\begin{tabular}{|c|c|c|}
\hline Dissatisfaction with sex life* & $\begin{array}{l}74(89.2) \\
3.52(1.66-7.48)\end{array}$ & $152(70.0)$ \\
\hline Loss of interest in sex & $\begin{array}{l}63(73.3) \\
2.12(1.22-3.67)\end{array}$ & $123(55.2)$ \\
\hline Pain or discomfort with intercourse & $\begin{array}{l}35(45.5) \\
1.28(0.75-2.18)\end{array}$ & $85(38.3)$ \\
\hline Not feeling close to partner* & $\begin{array}{l}19(21.6) \\
1.28(0.69-2.37)\end{array}$ & $40(17.9)$ \\
\hline Vaginal dryness & $\begin{array}{l}42(48.8) \\
0.94(0.57-1.56)\end{array}$ & $110(49.5)$ \\
\hline Vaginal itching & $\begin{array}{l}17(19.1) \\
1.50(0.77-2.94)\end{array}$ & $28(12.6)$ \\
\hline Vaginal discharge & $\begin{array}{l}11(12.8) \\
1.06(0.50-2.25)\end{array}$ & $29(13.1)$ \\
\hline Vaginal bleeding & $\begin{array}{l}3(3.4) \\
1.28(0.32-5.17)\end{array}$ & $7(3.1)$ \\
\hline
\end{tabular}

Self-image problems

Not feeling sexually attractive* $82(93.2)$ $189(84.8)$ 


\begin{tabular}{l|l|l}
\hline & $2.51(1.01-6.24)$ & \\
\hline Not able to feel like a woman* & $57(64.8)$ & $102(46.4)$ \\
\hline Bothered by weight change & $53(59.5)$ & \\
\hline Self-conscious about dress & $1.84(1.10-3.05)$ & $103(46.4)$ \\
\hline Bothered by hair loss & $45(51.1)$ & $67(29.9)$ \\
& $2.75(1.63-4.64)$ & \\
\hline Pain symptoms & $26(29.5)$ & $42(19.1)$ \\
\hline
\end{tabular}

Pain symptoms

\begin{tabular}{l|l|l}
\hline Joint pain & $48(54.5)$ & $128(57.9)$ \\
\hline Significant pain in certain parts of & $41(46.1)$ & $102(45.7)$ \\
body & $0.94(0.57-1.56)$ & \\
\hline Breast tenderness & $34(39.5)$ & $74(33.5)$ \\
\hline Headaches & $1.27(0.76-2.14)$ & \\
\hline Pain & $34(38.6)$ & $64(28.7)$ \\
& $1.62(0.96-2.74)$ & $71(31.7)$ \\
\hline
\end{tabular}

Vasomotor symptoms

\begin{tabular}{l|l|l}
\hline Hot flushes & $69(79.3)$ & $187(83.5)$ \\
& $0.71(0.38-1.34)$ & \\
\hline Night sweats & $56(63.6)$ & $170(75.9)$ \\
& $0.56(0.33-0.96)$ & \\
\hline
\end{tabular}




\begin{tabular}{|c|c|c|}
\hline \multicolumn{3}{|l|}{ Other physical symptoms } \\
\hline Poor sleep* & $\begin{array}{l}74(85.1) \\
0.86(0.42-1.75)\end{array}$ & $193(86.9)$ \\
\hline Lack of energy & $\begin{array}{l}57(64.0) \\
1.17(0.70-1.97)\end{array}$ & $138(61.3)$ \\
\hline Lightheadedness (ESS) & $\begin{array}{l}21(23.6) \\
1.22(0.67-2.20)\end{array}$ & $46(20.4)$ \\
\hline Shortness of breath & $\begin{array}{l}21(23.6) \\
1.95(1.03-3.71)\end{array}$ & $28(12.6)$ \\
\hline Feeling ill & $\begin{array}{l}14(15.7) \\
0.98(0.50-1.93)\end{array}$ & $37(16.6)$ \\
\hline
\end{tabular}

\section{Psychological symptoms}

\begin{tabular}{l|l|l}
\hline Depressive symptoms & $25(29.4)$ & $34(16.6)$ \\
& $2.14(1.18-3.89)$ & \\
\hline Anxiety symptoms & $23(27.7)$ & $196(22.5)$ \\
& $1.36(0.75-2.46)$ & \\
\hline
\end{tabular}

* Originally stated in the positive. Proportion presented is those who had the positive experience "somewhat", "a little bit" or "not at all". 
Acknowledgements: King Edward Memorial Hospital provided the facilities to house the Perth MSAC clinic.

Funding: The project was supported by an Australian National Breast Cancer Foundation Concept Award to Professors Hickey and Saunders. JLM is supported by a University of Melbourne Career Interruption Fellowship. MH is supported by an Australian National Health and Medical Research Council Practitioner Fellowship (grant number 1058935). The funders had no role in study design; in the collection, analysis and interpretation of data; in the writing of the report; nor in the decision to submit the article for publication.

\section{Figure legends}

Figure 1. Cancer types in partnered women $(n=316)$

Figure 2. Reasons partnered women were not sexually active $(n=89)$. Women could endorse more than one reason, so proportions do not sum to $100 \%$.

\section{$\underline{\text { References }}$}

[1] F. Bray, J.S. Ren, E. Masuyer, J. Ferlay, Global estimates of cancer prevalence for 27 sites in the adult population in 2008, Int J Cancer (2012).

[2] M. Ervik, F. Lam, J. Ferlay, I. Mery, I. Soerjomataram, F. Bray, Cancer Today. $<$ http://gco.iarc.fr/today/fact-sheets-populations?population=900\&sex=2>, 2016 (accessed 12 March.2017).

[3] M. Lee, Y.H. Kim, M.J. Jeon, Risk factors for negative impacts on sexual activity and function in younger breast cancer survivors, Psycho-Oncology 24(9) (2015) 1097-1103. [4] J.A.C. Cavalheiro, A.C.D. Bittelbrunn, C.H. Menke, J.V. Biazus, N.L. Xavier, R. Cericatto, F. Schuh, C.V. Pinheiro, E.P. Passos, Sexual function and chemotherapy in postmenopausal women with breast cancer, Bmc Womens Health 12 (2012).

[5] V. Sun, M. Grant, C.S. Wendel, C.K. McMullen, J.E. Bulkley, L.J. Herrinton, M.C. Hornbrook, R.S. Krouse, Sexual Function and Health-Related Quality of Life in Long-Term Rectal Cancer Survivors, J Sex Med 13(7) (2016) 1071-1079.

[6] B.L. Den Oudsten, M.J. Traa, M.S.Y. Thong, H. Martijn, I.H.J.T. De Hingh, K. Bosscha, L.V. van de Poll-Franse, Higher prevalence of sexual dysfunction in colon and rectal cancer survivors compared with the normative population: A population-based study, Eur J Cancer 48(17) (2012) 3161-3170.

[7] N. Biglia, G. Moggio, E. Peano, P. Sgandurra, R. Ponzone, R.E. Nappi, P. Sismondi, Effects of Surgical and Adjuvant Therapies for Breast Cancer on Sexuality, Cognitive Functions, and Body Weight, J Sex Med 7(5) (2010) 1891-1900.

[8] S.T. Lindau, L.P. Schumm, E.O. Laumann, W. Levinson, C.A. O'Muircheartaigh, L.J. Waite, A study of sexuality and health among older adults in the United States, New Engl J Med 357(8) (2007) 762-774. 
[9] M.E. Beutel, Y. Stobel-Richter, E. Brahler, Sexual desire and sexual activity of men and women across their lifespans: results from a representative German community survey, BJU Int 101(1) (2008) 76-82.

[10] R.A.M. Lonnee-Hoffmann, L. Dennerstein, P. Lehert, C. Szoeke, Sexual Function in the Late Postmenopause: A Decade of Follow-Up in a Population-Based Cohort of Australian Women, J Sex Med 11(8) (2014) 2029-2038.

[11] D.M. Lee, J. Nazroo, D.B. O'Connor, M. Blake, N. Pendleton, Sexual health and wellbeing among older men and women in England: findings from the English Longitudinal Study of Ageing, Arch Sex Behav 45(1) (2016) 133-144.

[12] A. Karraker, J. DeLamater, C.R. Schwartz, Sexual Frequency Decline From Midlife to Later Life, J Gerontol B-Psychol 66(4) (2011) 502-512.

[13] A. Nicolosi, E.O. Laumann, D.B. Glasser, E.D. Moreira, A. Paik, C. Gingell, G.S.S.A. Be, Sexual behavior and sexual dysfunctions after age 40: The global study of sexual attitudes and behaviors, Urology 64(5) (2004) 991-997.

[14] L.R. Schover, G.P. Baum, L.A. Fuson, A. Brewster, A. Melhem-Bertrandt, Sexual Problems During the First 2 Years of Adjuvant Treatment with Aromatase Inhibitors, J Sex Med 11(12) (2014) 3102-3111.

[15] J.M. Ussher, J. Perz, E. Gilbert, Sexual wellbeing and breast cancer in Australia: Experiences of people with breast cancer and health professionals, School of Psychology, University of Western Sydney, Sydney, Australia, and Breast Cancer Network Australia (BCNA), Melbourne, Australia, Melbourne, Australia, 2011.

[16] W.M. Vermeer, R.M. Bakker, G.G. Kenter, C.D. de Kroon, A.M. Stiggelbout, M.M. ter Kuile, Sexual issues among cervical cancer survivors: how can we help women seek help?, Psycho-Oncology 24(4) (2015) 458-464.

[17] J.L. Marino, C.M. Saunders, L.I. Emery, H. Green, D.A. Doherty, M. Hickey, How does adjuvant chemotherapy affect menopausal symptoms, sexual function, and quality of life after breast cancer?, Menopause 23(9) (2016) 1000-1008.

[18] J.L. Marino, C.M. Saunders, L.I. Emery, H. Green, D.A. Doherty, M. Hickey, Nature and severity of menopausal symptoms and their impact on quality of life and sexual function in cancer survivors compared with women without a cancer history, Menopause 21(3) (2014) 267-274.

[19] M. Hickey, J.L. Marino, S. Braat, S. Wong, A randomized, double-blind, crossover trial comparing a silicone-versus water-based lubricant for sexual discomfort after breast cancer, Breast Cancer Res Tr 158(1) (2016) 79-90.

[20] M. Hickey, L.I. Emery, J. Gregson, D.A. Doherty, C.M. Saunders, The multidisciplinary management of menopausal symptoms after breast cancer: a unique model of care, Menopause 17(4) (2010) 727-33.

[21] M. Hickey, C.M. Saunders, B.G. Stuckey, Management of menopausal symptoms in patients with breast cancer: an evidence-based approach, Lancet Oncol 6(9) (2005) 687-95. [22] K. Thirlaway, L. Fallowfield, J. Cuzick, The Sexual Activity Questionnaire: a measure of women's sexual functioning., Qual Life Res 5(1) (1996) 81-90.

[23] D. Cella, Manual for the Functional Assessment of Cancer Therapy (FACT) Quality of Life Instrument (version 4), Evanston Northwestern Health Care, Evanston, Illinois, 1997. [24] M.J. Brady, D.F. Cella, F. Mo, A.E. Bonomi, D.S. Tulsky, S.R. Lloyd, S. Deasy, M. Cobleigh, G. Shiomoto, Reliability and validity of the Functional Assessment of Cancer Therapy-Breast quality-of-life instrument, J Clin Oncol 15(3) (1997) 974-86.

[25] L.J. Fallowfield, S.K. Leaity, A. Howell, S. Benson, D. Cella, Assessment of quality of life in women undergoing hormonal therapy for breast cancer: validation of an endocrine symptom subscale for the FACT-B, Breast Cancer Res Treat 55(2) (1999) 189-99.

[26] J.G. Greene, Constructing a standard climacteric scale, Maturitas 29(1) (1998) 25-31. 
[27] S.D. Harlow, Gass, M., Hall, J.E., Lobo, R., Maki, P., Rebar, R.W., Sherman, S., Sluss, P.M., de Villiers, T.J. for the STRAW 10 Collaborative Group., Executive summary of the Stages of Reproductive Aging Workshop + 10: addressing the unfinished agenda of staging reproductive aging., Menopause 19(4) (2012) 387-395.

[28] H.N. Thomas, R. Hess, R.C. Thurston, Correlates of sexual activity and satisfaction in midlife and older women, Ann Fam Med 13(4) (2015) 336-342.

[29] S.E. Jackson, J. Wardle, A. Steptoe, A. Fisher, Sexuality After a Cancer Diagnosis: A Population-Based Study, Cancer-Am Cancer Soc 122(24) (2016) 3883-3891.

[30] L. Hendrickx, L. Gijs, P. Enzlin, Sexual difficulties and associated sexual distress in Flanders (Belgium): a representative population-based survey study, J Sex Med 13(4) (2016) 650-668.

[31] M.J. Traa, J.A. Roukema, J. De Vries, H.J. Rutten, B. Langenhoff, W. Jansen, B.L. Den Oudsten, Biopsychosocial predictors of sexual function and quality of sexual life: a study among patients with colorectal cancer, Transl Androl Urol 4(2) (2015) 206-17.

[32] G.A. Raggio, M.L. Butryn, D. Arigo, R. Mikorski, S.C. Palmer, Prevalence and correlates of sexual morbidity in long-term breast cancer survivors, Psychol Health 29(6) (2014) 632-650.

[33] E. Gilbert, J.M. Ussher, J. Perz, Sexuality after gynaecological cancer: A review of the material, intrapsychic, and discursive aspects of treatment on women's sexual-wellbeing, Maturitas 70(1) (2011) 42-57.

[34] E. Gilbert, J.M. Ussher, J. Perz, Sexuality after breast cancer: a review, Maturitas 66(4) (2010) 397-407.

[35] L. Brotto, S. Atallah, C. Johnson-Agbakwu, T. Rosenbaum, C. Abdo, E.S. Byers, C.

Graham, P. Nobre, K. Wylie, Psychological and interpersonal dimensions of sexual function and dysfunction, J Sex Med 13(4) (2016) 538-571. 